\title{
Obituaries
}

\section{Peter (Polly) Perrot}

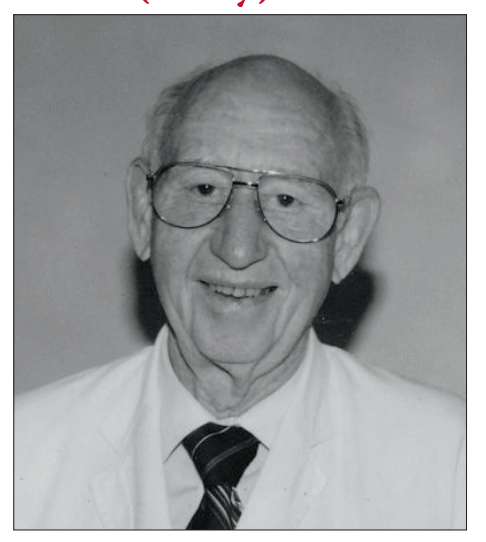

Polly, as he was usually called, was born in Port Elizabeth in 1925. $\mathrm{He}$ was the son of a PE radiologist, R Perrot. His primary schooling was at St Georges in PE. He then went on to St Andrews in Grahamstown, where he excelled in academics and became a prefect. He was an all-round sportsman and played cricket for

matriculating, he studied medicine for a year and then joined the SAMC. He was attached to the 9th Field Ambulance and saw service in Egypt and Italy. After the war, he completed his medical studies at the University of Cape Town (UCT) and qualified in 1950. He served his housemanship at King Edward VIII Hospital and then became a registrar at Addington Hospital, where I first met him. He was the most even-tempered man I have ever known. He was most popular with all the medical staff and was always prepared to help new interns. All in all, he was an excellent doctor. He loved fishing, and I remember when he caught a large Rock Cod that he kept in the hospital morgue, as it was the only refrigerated room in the hospital. Addington days were idyllic. As a group of nurses and doctors, we often spent a night at Campbells' Peace Cottage near the Umhlanga Lagoon.

In 1954, he married Merle Gebers, a physiotherapist. They had 3 children: John (now a dentist in Durban), Wendy (a physiotherapist in Australia) and Patricia (a teacher in Canada).

Polly showed an interest in gynaecology at an early stage in his career and spent 3 years at Addington and then 1 year at the Peninsula Maternity Hospital before going overseas and obtaining his MRCOG. He worked at various teaching hospitals in London and then returned to Durban, where he started private practice in 1958 . He was extremely popular and built up a large practice. I often worked with him when it was not clear whether a mass in the pelvis was a surgical or a gynaecological problem, and I was always impressed by his expertise.
He retired from active practice in 1997. Towards the end of his life, he became very withdrawn and lost his zest for living. He suffered a major stroke and shortly afterwards passed away on 6 August 2012. He is sadly missed by his family, his colleagues and his old patients.

\section{R O Wise}

wisel@mweb.co.za 